\title{
A Double-Blind, Placebo-Controlled Study of the Effectiveness of Mate Endurance TM Dietary Supplement on Sexual Satisfaction, Ejaculatory Control, and Distress in Men with Premature Ejaculation
}

\author{
Ali Teimouri' ${ }^{1}$, Vaheh Shivanian², James J. Elist ${ }^{1 *}$ \\ ${ }^{1}$ Department of Urology, MEC, Beverly Hills, CA, USA \\ ${ }^{2}$ Palmdale Regional Medical Center, Palmdale, CA, USA \\ Email: ali.teimouri.1994@gmail.com, vaheh_sh79@hotmail.com, *drelist@drelist.com
}

How to cite this paper: Teimouri, A., Shivanian, V. and Elist, J.J. (2020) A Double-Blind, Placebo-Controlled Study of the Effectiveness of Mate Endurance TM Dietary Supplement on Sexual Satisfaction, Ejaculatory Control, and Distress in Men with Premature Ejaculation. Open Journal of Urology, 10, 275-283.

https://doi.org/10.4236/oju.2020.1011032

Received: September 30, 2020

Accepted: November 10, 2020

Published: November 13, 2020

Copyright $\odot 2020$ by author(s) and Scientific Research Publishing Inc. This work is licensed under the Creative Commons Attribution International License (CC BY 4.0).

http://creativecommons.org/licenses/by/4.0/

(c) (i) Open Access

\begin{abstract}
Background: To assess the efficacy of the dietary supplement Mate Endurance on sexual satisfaction, ejaculatory control, and sexually related personal distress in patients with premature ejaculation. Methods: In a double-blind, randomized, placebo-controlled study, 68 patients between 21 and 60 years old with premature ejaculation were randomized to receive either Mate Endurance or placebo treatment for three months. The patients were provided a questionnaire at the start of the study and again three months post commencement of the study. The questionnaires were comprised of the Index of Premature Ejaculation (IPE) and the PE Diagnostic Tool (PEDT). Results: Participants in the treatment group experienced a significant improvement in symptoms often associated with premature ejaculation versus those in the placebo group. The treatment was widely used with limited adverse effects. Conclusions: The results of the study demonstrate the effectiveness of the dietary supplement Mate Endurance in improving symptoms associated with premature ejaculation, including general sexual satisfaction and distress associated with sexual encounters.
\end{abstract}

\section{Keywords}

Premature Ejaculation, Sexual Dysfunctions, Herbal, Ejaculation, Orgasm

\section{Introduction}

Premature ejaculation (PE) is the most common male sexual dysfunction affect- 
ing men and their partners, impacting 30\% - 40\% of men at some point in their lives [1]. There are three common symptoms that affect individuals with PE: a short time interval between penetration and ejaculation; little or no voluntary control of timing of ejaculation; and negative emotional consequences such as anxiety, embarrassment, reduced sexual satisfaction, the avoidance of sexual encounters, personal and/or partner distress, and interpersonal difficulties [2]. Premature ejaculation can be defined as persistent or recurrent ejaculation and orgasm before or immediately after vaginal penetration, and before the individual desires [3].

Assessment measures for PE include stopwatch measurements of intravaginal ejaculatory latency time (IELT) and the use of validated questionnaires [2]. While various studies have proposed that a PE diagnosis should be based solely on intravaginal ejaculatory latency time (IELT), the presence of other more subjective factors (such as perceived lack of control over ejaculation) has been directly associated with elevated personal distress related to ejaculation and decreased satisfaction with sexual intercourse, whereas the effects of IELT on these parameters are indirect [4]. Moreover, IELT has not been recommended for use in the clinical management of PE due to its potentially disruptive impact on sexual performance and pleasure. Currently, there are five validated questionnaires available for the assessment of PE. The Index of Premature Ejaculation (IPE) and the Premature Ejaculation Diagnostic Tool (PEDT) are the two most widely used questionnaires, given their extensive databases [5].

Effectively treating symptoms of PE is important, because sexual dysfunction can have a significant psychological impact on an individual's confidence, as well as a negative effect on an overall relationship. Available treatments for PE include psychological and behavioral therapy, topical therapy (e.g., Benzocaine wipes), and systemic treatments such as adrenergic antagonists, gamma-aminobutyric acid (GABA), and selective serotonin reuptake inhibitors (SSRIs). The success of these agents in addressing premature ejaculation has been variable, and the agents are associated with a host of side effects [6] [7]. Despite the prevalence of premature ejaculation, few therapies exist that offer minimal to no downside risk. Traditional Chinese Medicine, including herbal and natural products, is drug-free alternatives that have been suggested to improve sexual satisfaction with limited side effects in certain instances [8].

Mate Endurance is a dietary supplement that contains an herbal aphrodisiac blend concentrate with primary ingredients including L-Tryptophan, L-Citrulline, Cassia (Cinnamon) Bark Powder, Tribulus Fruit Extract, Grape Seed Extract, Vitamin B6, Vitamin B12, Pantothenic Acid, and L-Tyrosine. This study involved a randomized, double-blind placebo-controlled trial to evaluate the efficacy of the dietary supplement (Mate Endurance) on the improvement of sexual satisfaction, ejaculatory control, and distress associated with premature ejaculation. 


\section{Methods}

\subsection{The Herbal Compound}

The herbal compound (Mate Endurance) investigated in this study consisted of a blend of natural herbal concentrates packed in a gel capsule. Ingredients included in one serving were $3 \mathrm{mg}$ Niacin, $2 \mathrm{mg}$ Vitamin B6 (as Pyridoxine $\mathrm{HCl}$ ), $900 \mathrm{mcg}$ Vitamin B12 (as Cyanocobalamin), $5 \mathrm{mg}$ Pantothenic Acid (as Calcium-D-Pantothenate), $100 \mathrm{mcg}$ Selenium (as L-Selenomethionine) and a 224 mg proprietary blend of L-Tryptophan, L-Citrulline, Cassia (Cinnamon) Bark Powder, Fenugreek Seed Powder, Tribulus Fruit Extract, Grape Seed Extract, and L-Tyrosine.

\subsection{Placebo}

The placebo used in this study consisted of a tasteless starch compound with no active ingredients. The placebo was delivered in the same capsules used for the active herbal compound.

\subsection{Study Subjects}

Eligible subjects were healthy men aged 21 to 60 years old diagnosed with primary PE (based on the DSM-V criteria of premature ejaculation) [9]. Eligible subjects were also in a stable sexual relationship in which they engaged in sexual relations one or more times per week for a minimum of the last six months.

Exclusion criteria included: previous genital trauma or surgery, the presence of erectile dysfunction and inhibited male orgasm, a severe physical or mental illness, serious relationship problems, inability to engage in sexual intercourse once a week during the study period, current history of alcohol or drug abuse, and any history of diabetes mellitus, psychiatric disorders, renal insufficiency, liver diseases, dyslipidemia, hypertension, hypothyroidism or hyperthyroidism, or cardiac arrhythmias.

Sixty-eight men were deemed eligible for the study. All participants provided written informed consent prior to participating and after having been explained the possible risks and benefits associated with participation in the study. This study was approved by our institution's ethics committee.

\subsection{Study Procedures}

In a randomized, double-blind, placebo-controlled study conducted from December 2019 to March 2020, 68 male subjects complaining of primary PE were randomly assigned to two test groups (group 1 and group 2). Individuals in Group 1 received the herbal compound, and individuals in Group 2 received the placebo. Treatment was administered in a randomized sequence that remained unknown to the patient and the researchers. Subjects were instructed to take one capsule of their assigned treatment once daily on an empty stomach prior to their evening meal at approximately the same time every day. The use of medications or the consumption of alcoholic beverages within six hours of sexual ac- 
tivity was prohibited. Couples were instructed not to use condoms or topical anesthetic cream, to not pause during intercourse, or to have interrupted intromission. None of the subjects underwent formal psychosexual counseling.

Subjects were asked to complete the Index of Premature Ejaculation (IPE) and the Premature Ejaculation Diagnostic Tool (PEDT) both prior to and at the end of the study.

The Cronbach's alpha measure of internal consistency of the IPE scale in our studied population was 0.81 which indicated high reliability.

\subsection{Study Endpoints \& Method of Data Analysis}

The primary endpoints were increases in IPE scores and a decrease in PEDT scores, corresponding to a decrease in PE symptoms (i.e., more ejaculatory control, more sexual satisfaction, and less distress associated with sexual encounters). Safety endpoints included queries on potential adverse events. To compare two groups at different time points as well as the percent of changes during treatment, the Mann-Whitney test was used. The Wilcoxon singed-rank test was also applied to assess the within-group changes. Moreover, to evaluate the differences between groups after treatment while adjusting for measurement at baseline, the analysis of covariance (ANCOVA) was conducted. Differences were considered statistically significant at the level of a $P$-value of $\leq 0.05$. Statistical analysis was done using IBM SPSS 25.0.

\section{Results}

A total of 68 subjects were recruited; only 62 (91\%) completed the trial study. Six patients (9\%) dropped out of the study and were excluded from the final analysis (Figure 1). Mean patient age was $31.1 \pm 4.7$ years (range $24-41$ ) in Group 1 and $32.6 \pm 4.9$ years (range $23-44$ ) in Group 2 .

The mean pretreatment weekly intercourse episodes were 2.05 times per week for the herbal compound group compared to 2.03 times per week for the placebo group. The mean intercourse frequency at 12-week treatment was 2.14 times per week and 2.12 times per week for group 1 and group 2, respectively, which was not significantly different $(p=0.9)$.

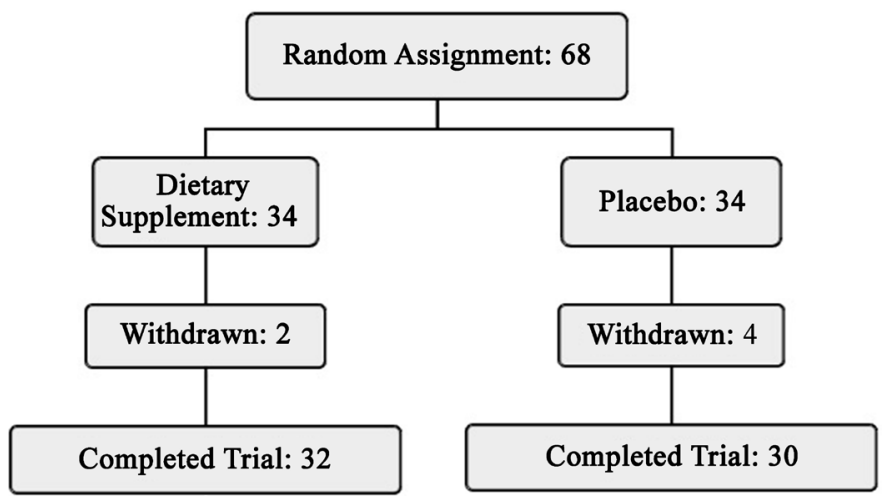

Figure 1. Study design. 
To analyze the PEDT results, baseline versus 12-week mean PEDT scores were compared. A score of 0 to 4 was attributed to each answer option in the PEDT questionnaire. A total score is calculated by taking the sum of each of the individual scores. A score of 11 or more is commonly found in men with PE.

The baseline mean PEDT score was 18 and 17 in Groups 1 and 2, respectively, at the commencement of the study. After 12 weeks of treatment, the mean PEDT score significantly decreased (18 to 10$)$ in the treatment group $(p<0.02)$, compared to only a mild decrease in the placebo group (17 to 15) $(p=0.06)$ (Table 1$)$.

Baseline and 12-week mean IPE Scores were also measured. In all three domains of sexual satisfaction, control, and distress, the two groups reported similar IPE scores at the commencement of the study $(\mathrm{p}>0.05)$. The scores in both the sexual satisfaction domain as well as in the distress domain showed statistically significant results 12 weeks after treatment both in unadjusted and adjusted analysis ( $\mathrm{p}<0.05$ ), while the differences between the two groups was not statistically significant in the control domain $(\mathrm{p}=0.524)$. The within-group changes were also assessed using the Wilcoxon signed-rank test. The increase in all domains, and both groups, were significant, but it was significantly higher in the treatment group (Table 2). A higher score represents more ejaculatory control, more sexual satisfaction, and less distress.

\section{Adverse Effects}

There were a slightly greater number of instances of adverse effects associated with the dietary supplement treatment compared to the placebo. Four individuals using the dietary supplement and one individual using the placebo reported treatment-related adverse events, including constipation (3 cases in Group 1), nausea (1 case in Group 2), and headache (1 case in Group 1).

\section{Discussion}

In this study, we evaluated the efficacy of Mate Endurance as a sexual complementary dietary supplement. To measure results, we used validated questionnaires, including the IPE and PEDT, as opposed to stopwatch measures of IELT. The use of validated questionnaires not only provided a more accurate means of measuring the subjective factors associated with PE, such as lack of ejaculatory

Table 1. Comparing PEDT results between two groups of mate endurance and Placebo.

\begin{tabular}{|c|c|c|c|c|}
\hline \multirow{2}{*}{ Variable } & \multirow{2}{*}{ Time } & \multicolumn{2}{|l|}{ Group } & \multirow{2}{*}{ p-value } \\
\hline & & Mate Endurance $(n=32)$ & Placebo $(n=30)$ & \\
\hline \multirow{4}{*}{ PEDT $^{\mathrm{a}}$} & Start of intervention & $18.0 \pm 1.0$ & $17.0 \pm 1.0$ & $<0.001^{\mathrm{b}}$ \\
\hline & 12 weeks past intervention & $10.0 \pm 2.0$ & $15.0 \pm 1.0$ & $<0.001^{\mathrm{b}}$ \\
\hline & Mean differential & $8.0 \pm 2.0$ & $2.0 \pm 1.0$ & $<0.001^{\mathrm{b}}$ \\
\hline & $\mathrm{p}$-value & $<0.02^{\mathrm{c}}$ & $0.06^{c}$ & \\
\hline
\end{tabular}

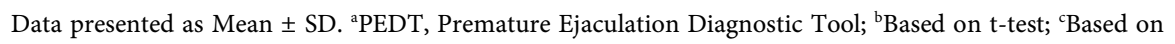
paired t-test. 
Table 2. Comparing Index of Premature Ejaculation (IPE) results between two groups of Mate Endurance and Placebo.

\begin{tabular}{|c|c|c|c|c|c|}
\hline \multirow[b]{2}{*}{ Domain } & \multirow[b]{2}{*}{ Time } & \multicolumn{2}{|c|}{ Group } & \multirow{2}{*}{$\begin{array}{l}\text { Unadjuste } \\
\mathrm{d} \text { p-value }\end{array}$} & \multirow{2}{*}{$\begin{array}{l}\text { Adjusted } \\
\text { p-value }\end{array}$} \\
\hline & & $\begin{array}{l}\text { Mate Endurance } \\
\quad(\mathrm{n}=32)\end{array}$ & $\begin{array}{l}\text { Placebo } \\
(\mathrm{n}=30)\end{array}$ & & \\
\hline \multirow{5}{*}{$\begin{array}{c}\text { Sexual } \\
\text { Satisfaction }\end{array}$} & $\begin{array}{c}\text { Start of } \\
\text { intervention }\end{array}$ & $\begin{array}{c}26.6 \pm 9.1 \\
25.0(125-50.0)\end{array}$ & $\begin{array}{c}25.2 \pm 4.8 \\
250(187-375)\end{array}$ & $0.547^{\mathrm{a}}$ & \multirow{4}{*}{$<0.001^{\mathrm{b}}$} \\
\hline & $\begin{array}{l}12 \text { weeks past } \\
\text { intervention }\end{array}$ & $\begin{array}{c}44.7 \pm 14.3 \\
50.0(25.0-68.7)\end{array}$ & $\begin{array}{c}30.0 \pm 9.9 \\
25.0(12.5-50.0)\end{array}$ & $<0.001^{\mathrm{a}}$ & \\
\hline & $\begin{array}{c}\text { Mean } \\
\text { differential }\end{array}$ & $\begin{array}{c}18.2 \pm 16.3 \\
15.6(0.0-43.7)\end{array}$ & $\begin{array}{c}4.8 \pm 11.1 \\
0.0(-12.5-31.2)\end{array}$ & $<0.001^{\mathrm{a}}$ & \\
\hline & p-value & $<0.001^{\mathrm{c}}$ & $0.033^{c}$ & & \\
\hline & $\begin{array}{c}\text { Start of } \\
\text { intervention }\end{array}$ & $\begin{array}{c}10.3 \pm 9.1 \\
6.2(0.0-25.0)\end{array}$ & $\begin{array}{c}11.7 \pm 6.7 \\
12.5(0.0-25.0)\end{array}$ & $0.397^{\mathrm{a}}$ & \multirow{2}{*}{$0.524^{\mathrm{b}}$} \\
\hline \multirow[t]{4}{*}{ Control } & $\begin{array}{l}12 \text { weeks past } \\
\text { intervention }\end{array}$ & $\begin{array}{c}17.2 \pm 8.2 \\
18.7(0.0-25.0)\end{array}$ & $\begin{array}{c}16.7 \pm 8.3 \\
18.7(0.0-31.2)\end{array}$ & $0.705^{\mathrm{a}}$ & \\
\hline & $\begin{array}{c}\text { Mean } \\
\text { differential }\end{array}$ & $\begin{array}{c}6.8 \pm 8.6 \\
3.1(0.0-25.0)\end{array}$ & $\begin{array}{c}5.0 \pm 7.7 \\
0.0(-6.2-18.7)\end{array}$ & $0.401^{\mathrm{a}}$ & \\
\hline & p-value & $<0.001^{\mathrm{c}}$ & $0.003^{c}$ & & \\
\hline & $\begin{array}{c}\text { Start of } \\
\text { intervention }\end{array}$ & $\begin{array}{c}9.8 \pm 9.9 \\
12.5(0.0-25.0)\end{array}$ & $\begin{array}{c}11.7 \pm 9.2 \\
12.5(0.0-25.0)\end{array}$ & $0.403^{\mathrm{a}}$ & $<0001^{\mathrm{b}}$ \\
\hline \multirow[t]{3}{*}{ Distress } & $\begin{array}{l}12 \text { weeks past } \\
\text { intervention }\end{array}$ & $\begin{array}{c}31.6 \pm 17.4 \\
25.0(0.0-50.0)\end{array}$ & $\begin{array}{c}18.3 \pm 10.7 \\
25.0(0.0-25.0)\end{array}$ & $0.005^{\mathrm{a}}$ & \\
\hline & $\begin{array}{c}\text { Mean } \\
\text { differential }\end{array}$ & $\begin{array}{c}21.9 \pm 17.7 \\
18.7(0.0-50.0)\end{array}$ & $\begin{array}{c}6.7 \pm 12.2 \\
0.0(-12.5-25.0)\end{array}$ & $0.001^{\mathrm{a}}$ & \\
\hline & p-value & $<0.001^{\mathrm{c}}$ & $0.007^{c}$ & & \\
\hline
\end{tabular}

Data presented as Mean $\pm \mathrm{SD}$, Median (min-max). ${ }^{\mathrm{a} B a s e d}$ on Mann-Whitney test; ${ }^{\mathrm{b}}$ Based on ANCOVA adjusted for measurements at the start of measurement; ${ }^{\mathrm{c} B a s e d}$ on Wilcoxon signed-rank test.

control and personal distress, but also eliminated the potentially disruptive impact on sexual performance and pleasure associated with stopwatch measurements.

At the commencement of the study, the treatment versus the placebo group showed no significant differences in mean age or mean IPE score. In addition, both Group A and Group B reported similar frequencies of weekly intercourse episodes pretreatment and during the 12-week treatment period. This suggests that both randomized groups had no significant differences prior to the treatment, allowing them to be compared fairly during the treatment period.

After 12 weeks of treatment, it was found that there was a significant decrease $(p<0.05)$ in the mean PEDT score and a significant increase $(p<0.05)$ in the mean IPE score in subjects in the dietary supplement treatment group, whereas there was a significantly smaller decrease in PEDT score and increase in IPE score in the placebo group. The reported changes in the placebo group can likely be attributed to the placebo effect. This suggests that the dietary supplement was more effective than a placebo in decreasing symptoms associated with $\mathrm{PE}$ as 
shown by the subject's responses to the questionnaire. Specifically, the supplement was effective in improving sexual satisfaction and decreasing distress stemming from sexual encounters in patients suffering from PE.

Various facets of Mate Endurance's formulation may have attributed to the overall effectiveness of the dietary supplement in all three domains of the IPE. First, tryptophan is a compound which enters the brain, where it is then converted to 5-Hydroxytryptophan (5-HTP), which increases the synthesis of serotonin [10]. Many neurotransmitters and receptors are found at the ejaculatory neuroaxis including dopamine, nitric oxide, and 5-hydroxytryptamine (5-HT), the precursor to serotonin [11]. Whereas dopamine causes excitation of the ejaculatory neuroaxis, serotonin causes inhibition [12]. Therefore, the increased presence of serotonin as a result of the consumption of L-Tryptophan may play an important role in ejaculatory control [13].

Next, L-citrulline is an ingredient which the body converts to L-arginine, an amino acid that improves blood flow through increased nitric oxide production. The increased presence of nitric oxide improves blood circulation, thereby improving erectile function [14].

Lastly, a combination of herbal ingredients presents in the dietary supplement such as fenugreek and tribulus terrestris have been suggested to increase sexual drive and libido in men [15].

The double-blind, placebo-controlled design, paired with the statistically significant results to improvements in factors often associated with premature ejaculation measured through the use of the IPE and PEDT, provides evidence of efficacy of the natural dietary supplement Mate Endurance for improvement of sexual satisfaction and decreased distress associated with premature ejaculation.

\section{Limitation}

Our study was limited by its small sample size, limited duration of follow-up, and using only self-reports to assess improvements in symptoms associated with PE.

\section{Conclusion}

Premature ejaculation continues to be one of the most predominant male sexual dysfunctions, affecting nearly $40 \%$ of men at one point in their lives. While it was believed that herbal supplements could provide a drug-free alternative solution, few studies have investigated the effectiveness of herbal supplements. The results of this study demonstrate the effectiveness of the dietary supplement Mate Endurance in improving some subjective symptoms of PE compared to placebo. Furthermore, Mate Endurance was well-tolerated by the subjects with minimum reported side effects.

\section{Conflicts of Interest}

The authors declare no conflicts of interest regarding the publication of this paper. 


\section{References}

[1] Patrick, D.L., Althof, S.E., Pryor, J.L., Rosen, R., Rowland, D.L., Ho, K.F., McNulty, P., Rothman, M. and Jamieson, C. (2005) Premature Ejaculation: An Observational Study of Men and Their Partners. The Journal of Sexual Medicine, 2, 358-367. https://doi.org/10.1111/j.1743-6109.2005.20353.x

[2] Althof, S.E., McMahon, C.G., Waldinger, M.D., Serefoglu, E.C., Shindel, A.W., Adaikan, P.G., Becher, E., Dean, J., Giuliano, F., Hellstrom, W.J.G., Giraldi, A., Glina, S., Incrocci, L., Jannini, E., McCabe, M., Parish, S., Rowland, D., Segraves, R.T., Sharlip, I. and Torres, L.O. (2014) An Update of the International Society of Sexual Medicine's Guidelines for the Diagnosis and Treatment of Premature Ejaculation (PE). Sexual Medicine, 2, 60-90. https://doi.org/10.1002/sm2.28

[3] Serefoglu, E.C., McMahon, C.G., Waldinger, M.D., Althof, S.E., Shindel, A., Adaikan, G., Becher, E.F., Dean, J., Giuliano, F., Hellstrom, W.J.G., Giraldi, A., Glina, S., Incrocci, L., Jannini, E., McCabe, M., Parish, S., Rowland, D., Taylor Segraves, R., Sharlip, I. and Torres, L.O. (2014) An Evidence-Based Unified Definition of Lifelong and Acquired Premature Ejaculation: Report of the Second International Society for Sexual Medicine Ad Hoc Committee for the Definition of Premature Ejaculation. The Journal of Sexual Medicine, 11, 1423-1441.

https://doi.org/10.1111/jsm.12524

[4] Shabsigh, R. and Rowland, D. (2007) The Diagnostic and Statistical Manual of Mental Disorders, Fourth Edition, Text Revision as an Appropriate Diagnostic for Premature Ejaculation. The Journal of Sexual Medicine, 4, 1468-1478. https://doi.org/10.1111/j.1743-6109.2007.00557.x

[5] Althof, S., Rosen, R., Symonds, T., Mundayat, R., May, K. and Abraham, L. (2006) Development and Validation of a New Questionnaire to Assess Sexual Satisfaction, Control, and Distress Associated with Premature Ejaculation. The Journal of Sexual Medicine, 3, 465-475. https://doi.org/10.1111/j.1743-6109.2006.00239.x

[6] Atikeler, M.K., Gecit, I. and Senol, F.A. (2002) Optimum Usage of Prilocaine-Lidocaine Cream in Premature Ejaculation. Andrologia, 34, 356-359.

https://doi.org/10.1046/j.1439-0272.2002.00511.x

[7] Higgins, A. (2010) Antidepressant-Associated Sexual Dysfunction: Impact, Effects, and Treatment. Drug, Healthcare and Patient Safety, 2, 141-150. https://doi.org/10.2147/DHPS.S7634

[8] Li, Y., Duan, Y., Yu, X., Wang, J., Yao, Z., Gong, X., Gong, X., Zheng, W., Xue, Y. and Guo, J. (2019) Traditional Chinese Medicine on Treating Premature Ejaculation. Medicine, 98, e15379. https://doi.org/10.1097/MD.0000000000015379

[9] American Psychiatric Association (2013) Diagnostic and Statistical Manual of Mental Disorders. 5th Edition. https://doi.org/10.1176/appi.books.9780890425596

[10] Richard, D.M., Dawes, M.A., Mathias, C.W., Acheson, A., Hill-Kapturczak, N. and Dougherty, D.M. (2009) L-Tryptophan: Basic Metabolic Functions, Behavioral Research and Therapeutic Indications. International Journal of Tryptophan Research, 2, 45-60. https://doi.org/10.4137/IJTR.S2129

[11] Giuliano, F. and Clément, P. (2012) Pharmacology for the Treatment of Premature Ejaculation. Pharmacological Reviews, 64, 621-644.

https://doi.org/10.1124/pr.111.004952

[12] Aggarwal, A., Lal Jethani, S., Rohatgi, R. and Kalra, J. (2017) The Role of Selective Serotonin Reuptake Inhibitors in Premature Ejaculation. European Medical Journal, 2, 78-81.

[13] Giuliano, F. and Clément, P. (2006) Serotonin and Premature Ejaculation: From 
Physiology to Patient Management. European Urology, 50, 454-466. https://doi.org/10.1016/j.eururo.2006.05.055

[14] Shirai, M., Hiramatsu, I., Aoki, Y., Shimoyama, H., Mizuno, T., Nozaki, T., Fukuhara, S., Iwasa, A., Kageyama, S. and Tsujimura, A. (2018) Oral L-Citrulline and Transresveratrol Supplementation Improves Erectile Function in Men with Phosphodiesterase 5 Inhibitors: A Randomized, Double-Blind, Placebo-Controlled Crossover Pilot Study. Sexual Medicine, 6, 291-296.

https://doi.org/10.1016/j.esxm.2018.07.001

[15] Ali, J., Ansari, S. and Kotta, S. (2013) Exploring Scientifically Proven Herbal Aphrodisiacs. Pharmacognosy Reviews, 7, 1. https://doi.org/10.4103/0973-7847.112832 